\title{
PresentACIÓN
}

\section{EL CEMENTERIO COMO LUGAR DE LA MEMORIA EUROPEA}

\section{THE CEMETERY AS A PLACE OF EUROPEAN MEMORY}

Recibido: 10/10/2021 - Aceptado: 20/11/2021

Doi: https://dx.doi.org/10.6018/rmu.495581

Publicado bajo licencia CC BY-SA

En los días previos al confinamiento decretado por el gobierno español por la crisis sanitaria provocada por la pandemia de Covid-19, la Sociedad Murciana de Antropología (SOMA) realizó -durante los días 6 y 7 de marzo de 2020 - el II Simposio internacional sobre culturas funerarias. Bajo el título «El cementerio como lugar de la memoria europea» se reunieron investigadores de Gran Bretaña, Alemania, los Países Bajos y España para abordar la dimensión social y patrimonial de nuestros cementerios, así como su relevancia para la identidad europea.

El Simposio fue resultado de la colaboración que SOMA realiza con el Ayuntamiento de Murcia desde el año 2015, cuyo principal objetivo es la investigación y divulgación de aspectos patrimoniales de la cultura funeraria. En esta cooperación, basada en un convenio firmado por ambas entidades, se elabora y publica anualmente una guía temática del cementerio municipal de Murcia, se han organizado numerosas visitas guiadas al camposanto y se realizó un primer simposio sobre culturas funerarias en 2018, cuyos resultados se publicaron en el número 26 (2019) de nuestra revista.

En esta ocasión, el número 28 (2021) de Revista Murciana de Antropología recoge las aportaciones del segundo simposio, así como la colaboración de otros investigadores. El tema objeto de estas aportaciones ha sido la reflexión sobre los cementerios como lugares de la memoria europea.

El primer artículo, escrito por Norbert Fischer, de la Universidad de Hamburgo, presenta una introducción conceptual sobre las nociones vinculadas con la memoria y los lugares de la memoria. Fischer expone cómo los cementerios reflejan las diversas interrelaciones entre muerte, sociedad y 
memoria, por lo que son el resultado de la vida cotidiana de cada sociedad, con sus ideologías, jerarquías sociales y otros aspectos socioculturales. El texto presenta el concepto paisaje de memoria aplicándolo al ejemplo de los cementerios europeos de la época burguesa.

En el segundo artículo, Julie Rugg, de la Universidad de York, ofrece una reflexión que aborda las interrelaciones entre la conservación, la investigación y la interpretación de los cementerios en los tiempos de un creciente interés por el turismo funerario. Parte de la constatación del aumento de un turismo interesado en cuestiones patrimoniales y los retos que esto supone para los cementerios como "patrimonio vivo".

La tercera aportación, de María Dolores Palazón Botella, de la Universidad de Murcia, es un estudio de la dimensión social y artística de determinadas tumbas excepcionales, como la del industrial Francisco Peña Vaquero, quien para su descanso eterno en el cementerio Nuestro Padre Jesús de Murcia construyó una tumba de hierro en la que refleja su dimensión profesional, su amor al trabajo y sus ideales cristianos.

Susanne Kitschun, responsable del cementerio de la revolución de 1848 de Berlín, presenta en el cuarto artículo una reflexión sobre este peculiar camposanto, su relevancia para la historia de la democracia en Europa y las remodelaciones que ha sufrido en diferentes contextos políticos.

En la siguiente aportación, el arquitecto e historiador holandés Jeroen Geurst realiza un estudio sobre uno de los paisajes centrales de la memoria europea actual: los cementerios militares. Como ejemplo ha elegido las creaciones del arquitecto británico Sir Edwin Lutyens, quien durante y después de la Gran Guerra diseñó una serie de cementerios con el objetivo de crear lugares de conmemoración nacional. Geurst analiza el lenguaje arquitectónico, así como la repercusión que ha tenido la obra de Lutyens.

A continuación, el también arquitecto e historiador Joachim Jacobs, de Berlín, presenta una visión de los cementerios judíos en la historia europea y su relevancia para la cultura y memoria del continente. Comenzando con los cementerios judíos en la antigua Roma, revisa la historia de estas llamadas "casas de la vida» como formas de una minoría que conserva sus tradiciones religiosas y funerarias.

Cierra el número la aportación de Pablo Jesús Lorite Cruz, doctor en Historia del Arte, que compara los antiguos rituales funerarios de velación e inhumación, en los que la presentación del cadáver tenía un papel fundamental, con los nuevos rituales de velación en los tanatorios, la cremación y los depósitos de cenizas, en los que la muerte se ha desdibujado y se oculta falsamente en la sociedad actual. 
Este número de Revista Murciana de Antropología forma parte del proyecto europeo "Aspectos culturales de la integración europea», que se lleva a cabo en el marco de la Cátedra Jean Monnet, cuyo titular es Klaus Schriewer, y que ha sido otorgada a la Universidad de Murcia para el periodo 2019-2022.

Klaus Schriewer

Pedro Martínez Cavero

Universidad de Murcia
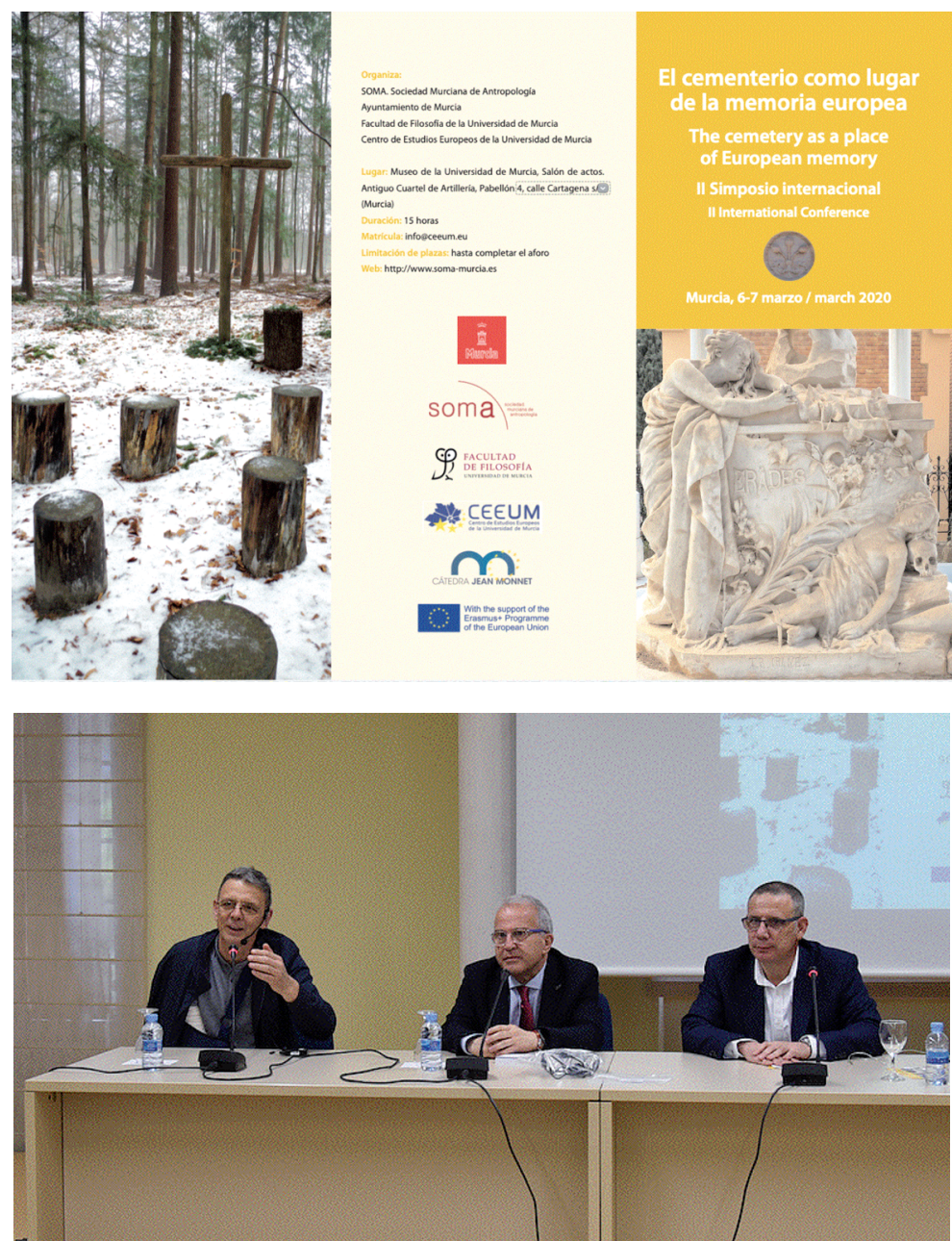

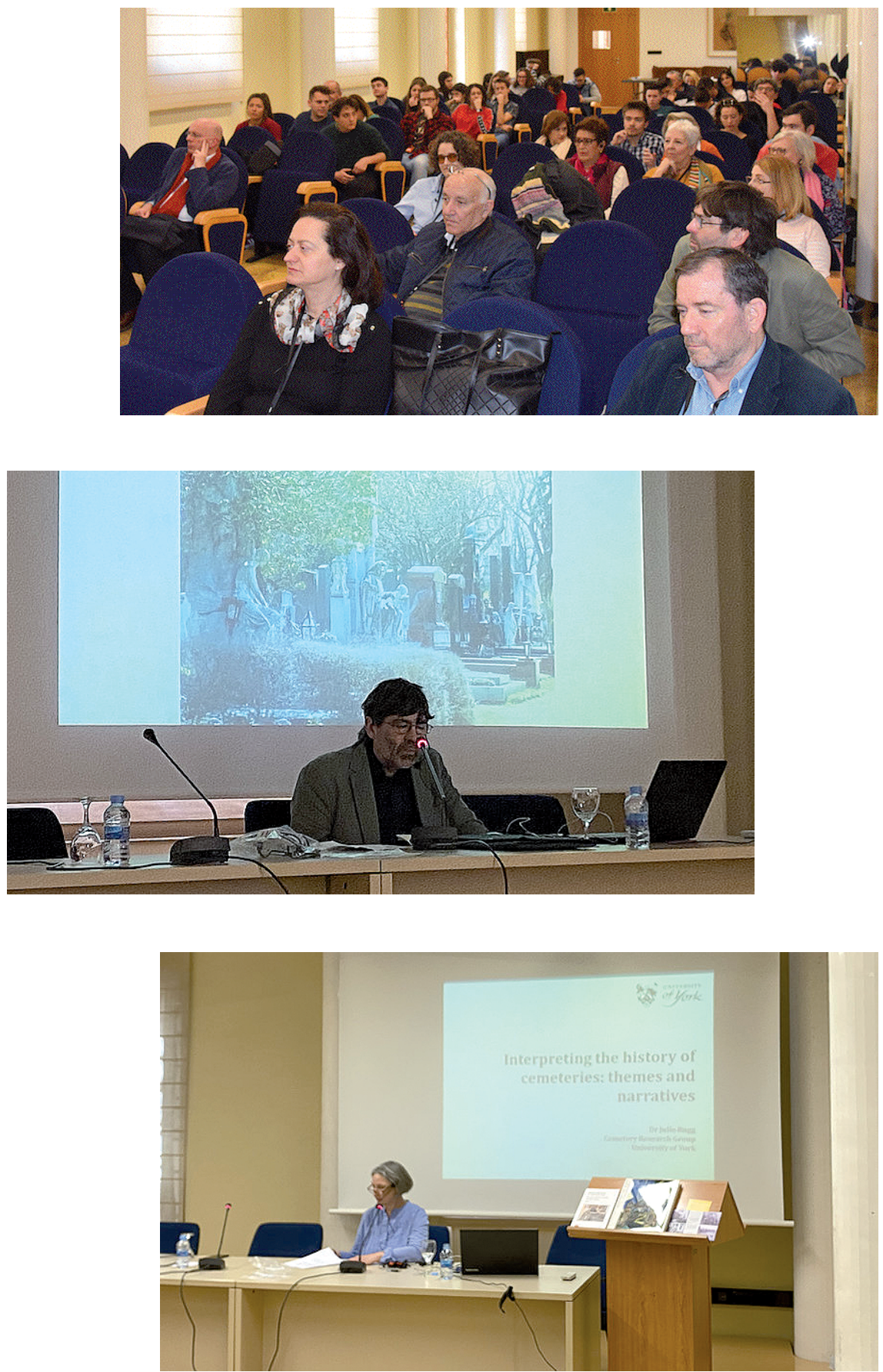
PRESENTACIÓN
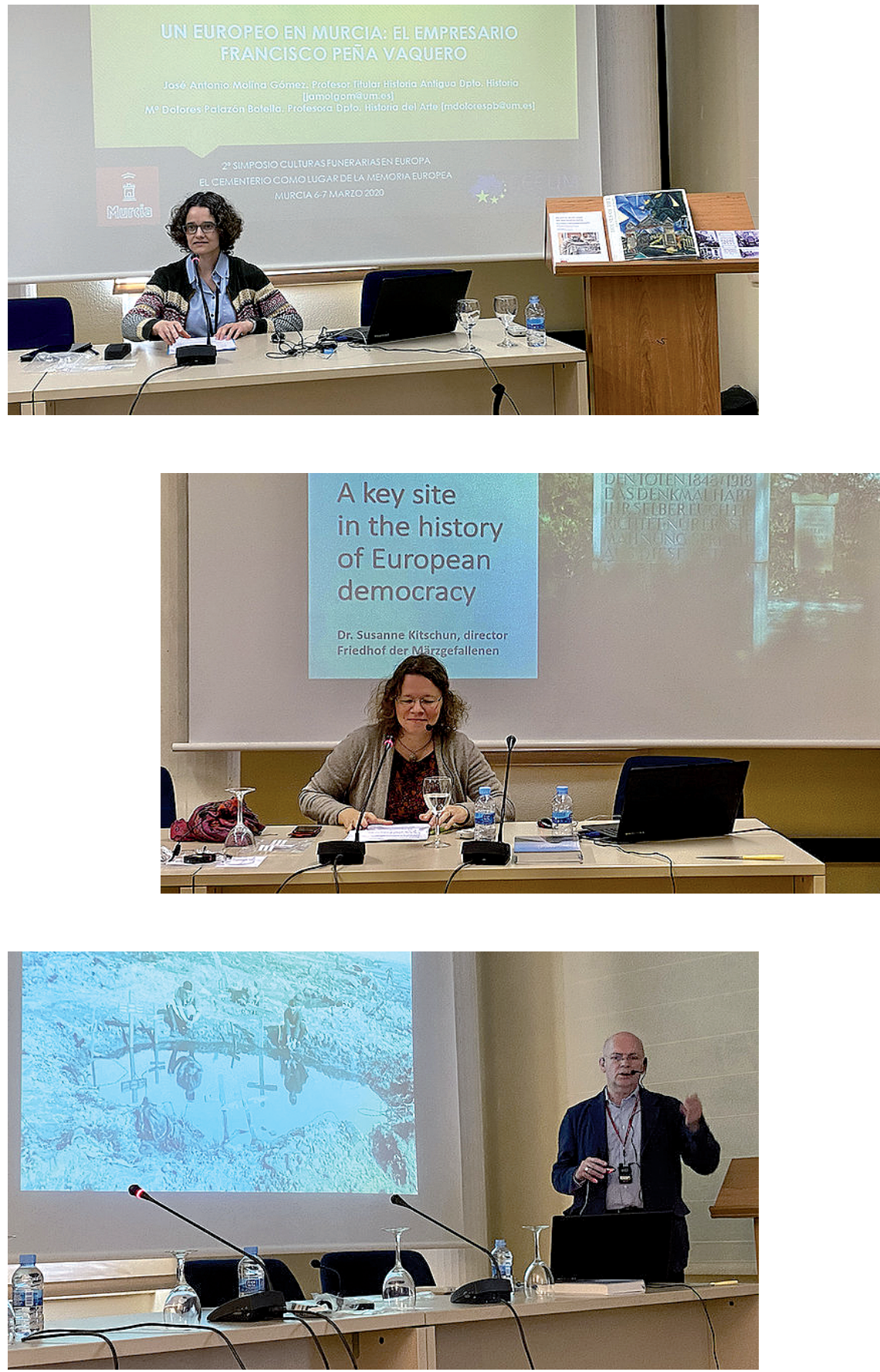

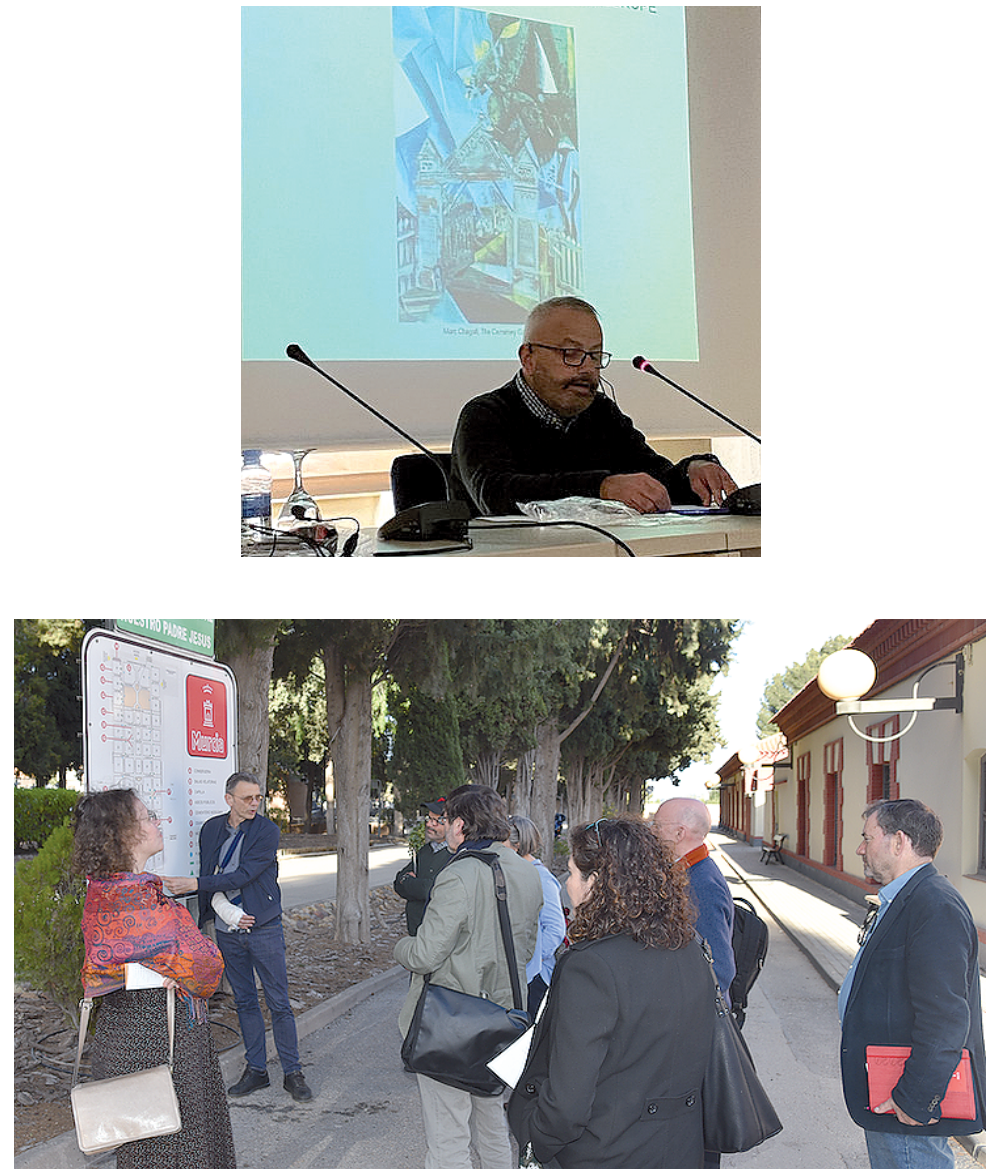